\title{
Immigration, Acculturation and Chronic Back and Neck Problems Among Latino-Americans
}

\author{
Quynh Bui · Mark Doescher · David Takeuchi • \\ Vicky Taylor
}

Published online: 1 August 2010

(C) The Author(s) 2010. This article is published with open access at Springerlink.com

\begin{abstract}
Higher acculturation is associated with increased obesity and depression among Latino-Americans, but not much is known about how acculturation is related to their prevalence of back and neck problems. This study examines whether acculturation is associated with the 12-month prevalence of self-reported chronic back or neck problems among US-born and immigrant Latinos. We performed multivariable logistic regression analysis of data from 2,553 noninstitutionalized Latino adults from the 2002-2003 National Latino and Asian American Survey (NLAAS). After adjusting for demographic, physical and mental health indicators, English proficiency, nativity and higher generational status were all significantly positively associated with the report of chronic back or neck problems. Among immigrants, the proportion of lifetime in the US was not significantly associated. Our findings suggest that the report of chronic back or neck problems is higher among more acculturated Latino-Americans independent of health status, obesity, and the presence of depression.
\end{abstract}

Keywords Acculturation - Back pain - Latino ·

Hispanic $\cdot$ Neck pain

This study has been reviewed and approved by the Institutional Review Board of the University of Washington.

Q. Bui $(\bowtie) \cdot$ M. Doescher

Department of Family Medicine, University

of Washington, Seattle, WA, USA

e-mail: quynh.bui@ucsfmedctr.org

D. Takeuchi

School of Social Work, University of Washington,

Seattle, WA, USA

V. Taylor

Fred Hutchinson Cancer Research Center, Seattle, WA, USA

\section{Introduction}

Among American adults, the three-month prevalence of having either back or neck pain is estimated to be as high as $31 \%$ [1]. They are leading causes of disability and Americans who reported having either chronic back or neck problems had about $65 \%$ greater yearly health care expenditures than those who did not [2].

The three-month prevalence of back pain is lower in Latino-Americans than in white Americans [3]. No studies in the US have examined whether the prevalence of chronic back or neck pain in Latino-Americans differs by acculturation. However, there is evidence that acculturation does affect the health of immigrants and of their descendants [4-24]. Factors associated with chronic back or neck pain, such as increased body mass index [25-31], depression, [32-40] smoking and heavy alcohol use [31, 41-43] have also been shown to be higher among more acculturated Latino-Americans [6, 16, 17, 20].

In Europe, certain immigrant populations have had higher prevalence of pain compared to native-born subjects [44, 45]. Immigrants from southern Europe and the Middle East living in Sweden have higher odds of chronic widespread pain, higher pain-associated psychosocial dysfunction, and higher rates of disability [45-48]. Similarly, South Asian immigrants residing in the United Kingdom had 3.7 times higher odds of reporting widespread musculoskeletal pain than native-born British [30]. Among these immigrants, higher acculturation was negatively associated with the report of widespread pain [44].

Very little is known about how culture affects the experience or report of chronic back or neck pain. One line of research suggests that the stress of the immigrant experience would lead to higher report of chronic back or neck problems among immigrant and less acculturated 
respondents. Alternatively, evidence of the deterioration of some health behaviors and outcomes in Latino-Americans with acculturation would lend support for the acculturation hypothesis which states that migrants from cultures with protective health practices experience worsening health with longer exposure to a host culture as they adopt the host culture's unhealthy practices $[4,7,23,24]$.

This study investigates whether the 12-month prevalence of chronic back or neck problems in Latino-Americans is associated with acculturation measured by nativity, generation in the US, percentage of lifetime in the US, and English proficiency. We hypothesize that the prevalence of reported chronic back or neck problems will be higher in more acculturated Latino-Americans and that differences in physical health, depression, and obesity may mediate the effect of acculturation.

\section{Methods}

\section{Sample and Data Collection}

The 2002-2003 National Latino and Asian American Study (NLAAS) is a national, representative, household survey of non-institutionalized adults aged 18 and older residing in the US who self-identified as Latino or Asian and spoke English, Spanish, Mandarin, Cantonese, Vietnamese, or Tagalog. The NLAAS employed two multi-stage probability sampling components: a core sampling of primary sampling units, area segments and housing units designed to be nationally representative of all US populations and a high-density supplemental sampling which oversampled geographic areas with greater than 5\% residential density of target ancestry groups (Latino: Cuban, Mexican, Puerto Rican; Asian: Chinese, Filipino, Vietnamese). Secondary respondents were recruited from households in which one eligible member had already been interviewed. Weighting adjustments developed for the NLAAS account for the joint probabilities for selection under this sampling design. The sample design and survey methods of the NLAAS have been described in detail elsewhere $[49,50]$.

The NLAAS-weighted sample is similar to the 2000 Census in age, sex, education, marital status, and geographic distribution but different in nativity and household income, with more US immigrants and lower income respondents in the NLAAS sample. This analysis focuses on LatinoAmerican NLAAS respondents. Although the NLAAS targeted Mexican, Puerto Rican, or Cuban individuals, those identifying other Latino ancestry were also surveyed. "Other Latinos" primarily included respondents from the Dominican Republic, Colombia, El Salvador, Ecuador, Guatemala, Honduras, Peru, and Nicaragua. A total of 2,554 LatinoAmericans (2009 primary respondents; 545 secondary respondents) were recruited between May 2002 and November 2003 as part of the larger NLAAS survey. The overall weighted response rate for Latinos was $75.5 \%$. Detailed sample characteristics have been reported by Heeringa et al. [51].

\section{Measures}

The NLAAS survey instruments have been translated and back-translated in Spanish, Mandarin, Cantonese, Vietnamese and Tagalog. A comprehensive process based on a cultural equivalence conceptual model was used to translate and adapt pre-validated measures. Other authors have described the development of the full survey instrument in detail [50].

\section{Chronic Back or Neck Problems}

The primary outcome of interest was the 12-month prevalence of chronic back or neck problems as reported using a standard chronic conditions checklist designed for use in cross-cultural epidemiological research as part of the World Mental Health Composite International Diagnostic Interview (WHO-CIDI) [52]. Respondents were considered to have had chronic back or neck problems or pain in the past 12 months if they answered "yes" to both the questions: "Have you ever had chronic back or neck problems?" and "During the past 12 months, did you still have chronic back or neck problems?"

\section{Nativity and Acculturation Measures}

Acculturation is a complex concept that describes the process that occurs when contact between two cultures results in substantial change in the culture of the individual members of one or both groups [17]. Four measures were used to approximate acculturation: nativity, generational status, self-rated English proficiency, and percentage of lifetime spent in the US. Nativity was defined by whether the respondent reported having been born in or outside the US. Puerto Ricans were considered US-born if they were born in one of the fifty US states and were considered immigrants if they were born in Puerto Rico or another country. Generational status was defined with immigrants as the first generation. Respondents were categorized as belonging to the second generation if they were US-born and had at least one immigrant parent. US-born respondents with two US-born parents were considered to belong to the third generation or greater. Respondents rated their English oral proficiency as "excellent", "good", "fair" or "poor." The proportion of the respondent's lifetime spent in the US was applied only to immigrants and was constructed by dividing the number of years spent in the US by 
the respondent's current age and is used to partially account for the age at immigration as well as the time spent in the US $[5,53,54]$.

\section{Health Measures}

The respondent provides a self-rating of physical health by answering the question, "How would you rate your overall physical health - excellent, very good, good, fair, or poor?" Smoking status was dichotomized into current smoker and current non-smoker. Body mass index (BMI) is defined as the body weight in kilograms divided by the height in meters squared and was dichotomized at obese (BMI of 30 or greater) and not obese.

The NLAAS mental health interview was based on the WMH-CIDI [55]. The NLAAS used WMH-CIDI modules to measure the lifetime prevalence of alcohol abuse and the combined 12-month prevalence of two depressive disorders: major depression and dysthymia. Alcohol abuse and depression were modeled as dichotomous variables. Respondents were considered to have had alcohol abuse in their lifetime if they had ever met diagnostic criteria for alcohol abuse from the Diagnostic and Statistical Manual of Mental Disorders. They were considered to have depression if they met criteria for either major depression or dysthymia in the last year.

\section{Socio-Demographic Measures}

Socio-demographic measures included age, sex, years of education and household income. Age is rescaled such that one unit of age is equal to 10 years. Years of education were divided into four categories: less than 12 years, 12 years, 13-15 years, and greater than 16 years of schooling. Household income was modeled as percentage of the federal poverty level in four categories: below poverty level, $100 \%$ to less than $200 \%, 200 \%$ to less than $300 \%$, and $300 \%$ of poverty level or greater.

\section{Statistical Analysis}

All statistical analyses were performed using STATA statistical software package (version 9.2) [56]. We used crosstabulation to illustrate the distributions of demographic and immigration variables in the NLAAS data. Using the US Latino population as a denominator, we computed age- and sex-adjusted 12-month prevalence of chronic back or neck problems across Latino ethnic subgroups and immigration groups. Weighted percentage estimates and 95\% confidence intervals are reported.

We modeled the association between the 12-month prevalence of chronic back or neck problems and our measures of acculturation using weighted logistic regression analysis with adjustments for age, sex, income, education, self-rated physical health, obesity, depressive disorder in the past 12 months, alcohol abuse, and smoking status. Standard error estimates from logistic regression models were adjusted for the complex sampling design using a first-order Taylor series approximation [57]. We conducted significance tests using a design-adjusted Wald test. For logistic regression analyses, we report prevalence ratios with $95 \%$ confidence intervals estimated using methodology described by Zhang and $\mathrm{Yu}$ [58].

The University of Washington institutional review board has reviewed and approved this study.

\section{Results}

Table 1 shows the unweighted study sample characteristics for Latino-Americans stratified by the presence of reported chronic back or neck problems in the last 12 months. Mexican-Americans were the largest ethnic group. The group reporting chronic back or neck problems had greater numbers of respondents who were obese, currently smoking, in fair or poor health, or had depressive disorder or alcohol abuse.

The weighted age- and sex-adjusted 12-month prevalence of chronic back or neck problems in all Latinos sampled was $14.6 \%(13.2,16.0)$. This prevalence was significantly lower for immigrant Latinos $(12.0 \%, 95 \% \mathrm{CI}$ : $10.3,13.8)$ than for US-born Latinos $(20.2 \%, 95 \%$ CI: 17.1 , 23.8). This pattern was consistent and significant in each of the largest Latino ethnic subgroups (Table 2).

Unadjusted associations presented in Table 3 showed that being born in the US, belonging to the third or greater generation, and reporting good or excellent English proficiency were all associated with significantly higher risk of reporting chronic back or neck problems in the past 12 months. Those who reported obesity, poorer physical health, depression, alcohol abuse, or current smoking also had significantly greater risk of reporting chronic back or neck problems compared to those who did not have these characteristics.

Model 1 in Table 3 shows the relative risks of reporting chronic back or neck problems in the past 12 months by generation adjusted for English proficiency, age, sex, and ethnicity. Compared to immigrants, Latinos in the third generation or greater were 1.6 times more likely to report chronic back or neck problems but second generation Latinos were not at greater risk. Good or excellent English proficiency was also associated with about 1.6 times the risk of chronic back or neck problems and was independent of generational status.

Model 2 also adjusts for education, poverty level, selfreported health status, depression and alcohol abuse. 
Table 1 Sample characteristics of Latino respondents from the National Latino- and Asian-American study, 2002-2003

\begin{tabular}{|c|c|c|c|}
\hline Variable & $\begin{array}{l}\text { Latinos } \\
(n=2,553) \\
(\%)\end{array}$ & $\begin{array}{l}\text { Without back and neck } \\
\text { problems }(n=2,137) \\
(\%)\end{array}$ & $\begin{array}{l}\text { With back and neck } \\
\text { problems }(n=416) \\
(\%)\end{array}$ \\
\hline Male & 44.1 & 45.5 & 38.9 \\
\hline Mean age (SD) & $40.6(15.6)$ & $39.8(15.5)$ & $44.9(15.7)$ \\
\hline \multicolumn{4}{|l|}{ Ethnicity } \\
\hline Mexican $(n=868)$ & 34.0 & 22.3 & 24.3 \\
\hline Puerto Rican $(n=495)$ & 19.4 & 18.4 & 24.3 \\
\hline Cuban $(n=577)$ & 22.6 & 34.8 & 29.8 \\
\hline Other Latino $(n=614)$ & 24.0 & 24.5 & 21.6 \\
\hline Nativity_born in US & 36.2 & 34.9 & 43.0 \\
\hline \multicolumn{4}{|l|}{ Generational status } \\
\hline 1st Generation (immigrants) & 64.1 & 65.1 & 57.0 \\
\hline 2nd Generation & 20.3 & 20.3 & 21.4 \\
\hline 3rd Generation or greater & 15.7 & 14.6 & 21.6 \\
\hline \multicolumn{4}{|c|}{ Percent of lifetime in US (Immigrants only) $(n=1630)$} \\
\hline $0-25 \%$ Lifetime in US & 26.0 & 26.6 & 23.0 \\
\hline $25-50 \%$ Lifetime in US & 30.3 & 31.4 & 24.3 \\
\hline 50-99\% Lifetime in US & 43.7 & 42.1 & 52.8 \\
\hline English proficient & 50.4 & 49.8 & 55.9 \\
\hline \multicolumn{4}{|l|}{ Income } \\
\hline Below poverty level & 25.0 & 24.2 & 28.1 \\
\hline $100-199 \%$ Of poverty level & 21.2 & 20.8 & 21.4 \\
\hline $200-299 \%$ Of poverty level & 13.2 & 13.0 & 12.7 \\
\hline $300 \%$ Or greater of poverty level & 40.7 & 42.0 & 37.7 \\
\hline \multicolumn{4}{|l|}{ Education } \\
\hline 11 years or less & 39.2 & 38.7 & 39.9 \\
\hline 12 years & 25.0 & 25.3 & 22.4 \\
\hline $13-15$ years & 29.5 & 29.3 & 32.0 \\
\hline 16 years or greater & 6.3 & 6.8 & 5.8 \\
\hline \multicolumn{4}{|l|}{ Physical health rating } \\
\hline Excellent & 17.3 & 19.4 & 5.5 \\
\hline Very good & 24.6 & 26.0 & 20.0 \\
\hline Good & 30.4 & 30.8 & 28.4 \\
\hline Fair/poor & 27.7 & 23.7 & 46.0 \\
\hline $\mathrm{BMI}-30$ or greater & 27.0 & 25.4 & 35.1 \\
\hline Affective disorder in past 12 months & 9.9 & 8.1 & 19.5 \\
\hline Alcohol abuse in lifetime & 8.8 & 7.9 & 14.2 \\
\hline Current smoker & 20.2 & 19.0 & 25.0 \\
\hline
\end{tabular}

Depression in the last 12 months was associated with almost twice the likelihood of chronic back or neck problems while each unit of poorer self-rated physical health was associated with a $34 \%$ increase in risk. Belonging to the third generation or greater continued to be significantly positively associated with chronic back or neck problems but the relative risk was attenuated $(1.31,95 \%$ CI 1.01 , 1.67). English proficiency was associated with 1.67 times the risk of reporting chronic back or neck problems.
Obesity and alcohol abuse also remained positively associated.

In another weighted logistic analysis, we looked at whether differences exist among immigrants using proportion of lifetime in the US and English proficiency as measures of acculturation. In a model that was adjusted for age, sex, ethnicity, education, poverty level, and health indicators but not for English proficiency, no significant association was found between proportion of lifetime in the 
Table 2 Weighted age- and sex-adjusted 12-month prevalence of chronic back or neck problems by ethnicity and nativity

Prevalence \% $(95 \% \mathrm{CI})$

\begin{tabular}{ll}
\hline Latino & $14.6(13.2,16.0)$ \\
Total & $12.0(10.3,13.8)$ \\
Immigrant & $20.2(17.1,23.8)$ \\
US born & \\
Mexican & $14.9(13.5,16.5)$ \\
Total & $11.8(10.3,13.6)$ \\
Immigrant & $19.9(16.5,23.7)$ \\
US born & \\
Puerto Rican & $17.2(13.9,21.0)$ \\
Total & $12.8(9.7,16.7)$ \\
Immigrant & $21.3(17.2,26.2)$ \\
US born & \\
Cuban & $13.2(11.2,15.4)$ \\
Total & $12.3(10.2,14.7)$ \\
Immigrant & $20.6(17.4,24.2)$ \\
US born & \\
Other Latinos & $13.4(11.3,15.9)$ \\
Total & $11.4(9.5,13.6)$ \\
Immigrant & $19.2(14.9,24.4)$ \\
US born &
\end{tabular}

Age and sex adjusted to US Latino population means

US and report of chronic back or neck problems in the last 12 months. Respondents who had been in the US for 50 to $75 \%$ of their lifetime had a relative risk of $0.6(95 \% \mathrm{CI}$ : $0.34,1.04)$ for chronic back or neck problems compared to those who had spent less than $25 \%$ of their lifetime in the US. Those who had greater than $75 \%$ of their lifetime in the US had a relative risk of 0.97 (95\% CI: $0.52,1.79)$ for chronic back or neck problems (data not shown).

Among immigrants, English proficiency was associated with a $61 \%$ increased risk of chronic back or neck problems $(1.61,95 \%$ CI: $1.18,2.14)$ in an adjusted model that did not include proportion of lifetime in the US, but was not significant $(1.5,95 \%$ CI: $0.95,2.29)$ when proportion of lifetime in the US was included (data not shown). A similar analysis using years residing in the US and age at immigration did not yield any significant differences in chronic back or neck problems by these measures of acculturation.

\section{Discussion}

These findings support the hypothesis that the report of chronic back or neck pain is associated with acculturation in Latino-Americans. While we found a strong association between chronic back or neck problems and obesity, depression and poorer self-rated physical health, these factors did not completely explain the observed generational or language associations.

Our findings apparently contradict those of a similar study conducted among South Asians in the United Kingdom where higher acculturation was negatively associated with reports of widespread pain [44]. Possibly, the relative prevalence of health behaviors between the culture of origin and the host culture helps determine the direction of change in health behavior and ultimately in health outcome [24]. In the case of back or neck pain, immigrants and their descendants who originate from a culture of low prevalence of back or neck pain entering a culture of high prevalence would show an increase in back or neck pain prevalence with acculturation. Likewise, individuals coming from a culture of high back or neck pain prevalence entering a culture of low prevalence would experience lower back or neck pain prevalence with acculturation. This model of acculturation would predict that the prevalence of back or neck pain in the United States is high relative to the countries of origin of the Latino respondents in this survey, while this prevalence is higher in the countries of south Asia than in the United Kingdom. While direct cross-national comparisons are not available, comparisons that do exist suggest that prevalence of chronic pain in the United States is high compared to other developed and developing nations [33]. Other crossnational comparisons of back pain prevalence revealed the United Kingdom to have a low prevalence compared to other developed nations [59,60]. Although this evidence is not adequate to support this model of acculturation, it reveals a possible future direction for research in this area.

We found a consistent positive association between English proficiency and the report of chronic back or neck pain, even though the survey was conducted in the language in which the respondent was more fluent. This finding suggests that language acculturation may be associated with changes in certain health related concepts such as the definitions of back or neck pain or chronicity. Alternatively, English proficiency, even independent of generational status, might be associated with other aspects of lifestyle such as type of work, social networks, or health behaviors (e.g., physical activity) which may affect back or neck pain. Whether acculturation is related to the actual experience of back or neck problems, the reporting of these problems, or both cannot be determined from this study. These findings are compatible with other studies which have found differing health behaviors, reporting, or outcomes based on linguistic differences [5, 7, 23].

Our results indicate a strong relationship between physical health, depression and the report of chronic back or neck pain. They are consistent with cross-national findings from the World Mental Health Survey which have shown significant positive associations between the report 
Table 3 Unadjusted and adjusted prevalence ratios between 12-month report of back or neck problems and acculturation, socio-demographic, and health factors

\begin{tabular}{|c|c|c|c|}
\hline & $\begin{array}{l}\text { Unadjusted associations } \\
\text { PR }(95 \% \mathrm{CI})\end{array}$ & $\begin{array}{l}\text { Model } 1 \\
\text { PR }(95 \% \text { CI })\end{array}$ & $\begin{array}{l}\text { Model } 2 \\
\text { PR (95\% CI) }\end{array}$ \\
\hline Nativity-born in US & $1.66(1.29,2.11)^{* * *}$ & & \\
\hline 1st Generation (immigrants) & & Referent & Referent \\
\hline 2nd Generation & $1.04(0.77,1.39)$ & $1.04(0.73,1.43)$ & $0.90(0.65,1.24)$ \\
\hline 3rd Generation or greater & $1.88(1.41,2.44)^{* * *}$ & $1.63(1.17,2.23)^{* *}$ & $1.31(1.01,1.67)^{*}$ \\
\hline English proficient & $1.73(1.37,2.15)^{* * *}$ & $1.60(1.23,2.03)^{* *}$ & $1.67(1.33,2.05)^{* * *}$ \\
\hline Age (10 years) & $1.14(1.04,1.23)^{* *}$ & $1.17(1.06,1.28)^{* *}$ & $1.13(1.03,1.23)^{* *}$ \\
\hline Female & $1.32(1.03,1.24)^{*}$ & $1.28(1.00,1.61)$ & $1.22(0.96,1.54)$ \\
\hline Mexican & $0.86(0.73,1.01)$ & Referent & Referent \\
\hline Puerto Rican & $1.35(1.10,1.66)^{* *}$ & $1.27(1.03,1.57)^{*}$ & $1.32(1.03,1.67)^{*}$ \\
\hline Cuban & $0.89(0.68,1.15)$ & $1.06(0.70,1.38)$ & $1.18(0.92,1.48)$ \\
\hline Other Latino & $1.06(0.84,1.32)$ & $1.08(0.86,1.35)$ & $1.17(0.97,1.4)$ \\
\hline Education-11 years or less & $0.94(0.75,1.16)$ & & Referent \\
\hline Education-12 years & $0.91(0.61,1.30)$ & & $0.93(0.62,1.33)$ \\
\hline Education-13-15 years & $1.16(0.87,1.52)$ & & $1.13(0.81,1.52)$ \\
\hline Education-greater than 16 years & $1.08(0.69,1.63)$ & & $1.21(0.72,1.84)$ \\
\hline Below poverty level & $0.90(0.69,1.16)$ & & $1.05(0.81,1.34)$ \\
\hline $100-199 \%$ Of poverty level & $1.17(0.84,1.58)$ & & $1.20(0.83,1.64)$ \\
\hline $200-299 \%$ Of poverty level & $0.94(0.63,1.37)$ & & $1.15(0.74,1.67)$ \\
\hline $300 \%$ Or greater of poverty level & $1.00(0.77,1.29)$ & & Referent \\
\hline Low physical health rating & $1.44(1.33,1.57)^{* * *}$ & & $1.34(1.23,1.45)^{* * *}$ \\
\hline DSM-IV criteria for affective disorder in past 12 months & $2.65(1.84,3.61)^{* * *}$ & & $1.97(1.36,2.61)^{* * *}$ \\
\hline $\mathrm{BMI}-30$ or greater & $1.67(1.40,1.99)^{* * *}$ & & $1.35(1.1,1.62)^{* *}$ \\
\hline DSM-IV criteria for alcohol abuse in lifetime & $1.94(1.40,2.60)^{* * *}$ & & $1.52(1.03,2.09)^{*}$ \\
\hline Current smoker & $1.38(1.08,1.74)^{*}$ & & $1.21(0.96,1.49)$ \\
\hline
\end{tabular}

Model 1 adjusted for generation, English proficiency, age, sex, and ethnicity. Model 2 added adjustment for education, poverty level, self-rated physical health, affective disorder, overweight, alcohol abuse, and smoking

Two-tailed $P$-values: * $P \leq 0.05$; ** $P \leq 0.01$; *** $P \leq 0.001$

of chronic pain and that of poor physical health, affective dysfunction, and alcohol abuse [33, 61, 62]. Our findings further support the assertion that the relationship between chronic pain and psychological dysfunction is consistent cross-culturally.

This study is the first to demonstrate an association between acculturation and chronic back or neck problems among Latino-Americans. Its strengths lie in the use of data from a national representative survey conducted in both English and Spanish and developed with attention to cross-cultural meanings of survey items [63]. We were able to adjust for many social and physical factors that may influence the experience or report of chronic back pain [64].

Our study has a number of limitations. As the National Latino and Asian American Study is cross-sectional, causal relationships cannot be determined. Additionally, the report of chronic back or neck problems is not precisely defined or clinically validated. However, self-reports of chronic conditions have been found to have good correlation with medical records in several methodological studies [65, 66], and the use of chronic condition checklists has been found to elicit more complete reporting than the use of open-ended questions [67]. Martin et al. used Medical Expenditure Panel Survey data to show that about $78 \%$ of complaints of back or neck problems that carried diagnostic codes had codes that corresponded to "intervertebral disk disorders," "sprains and strains of the back," and "other and unspecified disorders of back," which include diagnoses of lumbago, backache, and unspecified symptoms of the back [2]. Another limitation is the lack of adequate power to examine associations within specific ethnic groups. Weighted age- and sex-adjusted prevalence by the largest ethnic groups in this survey revealed a consistent pattern of higher report of chronic back and neck problems among US-born respondents. Finally, we did not have data on physical activity and work-related factors that might affect the experience or report of chronic back or 
neck pain. Other unmeasured confounders may affect findings.

Future research should include longitudinal studies to clarify causal relationships between acculturative processes and chronic pain conditions. Further investigation into the possible connections between chronic pain and specific changes in lifestyle, attitudes, and stressors related to immigration and acculturation are warranted. Future studies should also examine differences that may exist across specific ethnic groups.

Open Access This article is distributed under the terms of the Creative Commons Attribution Noncommercial License which permits any noncommercial use, distribution, and reproduction in any medium, provided the original author(s) and source are credited.

\section{References}

1. Strine TW, Hootman JM. US national prevalence and correlates of low back and neck pain among adults. Arthritis Rheum. 2007; 57(4):656-65.

2. Martin BI, Deyo RA, Mirza SK, et al. Expenditures and health status among adults with back and neck problems. JAMA. 2008;299(6):656-64.

3. Deyo RA, Mirza SK, Martin BI. Back pain prevalence, visit rates: estimates from U.S. national surveys, 2002. Spine. 2006;31(23): 2724-7.

4. Lassetter JH, Callister LC. The impact of migration on the health of voluntary migrants in western societies. J Transcult Nurs. 2009;20(1):93-104.

5. Eamranond PP, Legedza AT, Diez-Roux AV, et al. Association between language and risk factor levels among Hispanic adults with hypertension, hypercholesterolemia, or diabetes. Am Heart J. 2009;157(1):53-9.

6. Yeh MC, Viladrich A, Bruning N, Roye C. Determinants of Latina obesity in the United States: the role of selective acculturation. J Transcult Nurs. 2009;20(1):105-15.

7. Corral I, Landrine H. Acculturation and ethnic-minority health behavior: a test of the operant model. Health Psychol. 2008;27(6): 737-45.

8. Gollenberg A, Pekow P, Markenson G, Tucker KL, Chasan-Taber L. Dietary behaviors, physical activity, and cigarette smoking among pregnant Puerto Rican women. Am J Clin Nutr. 2008;87(6): 1844-51.

9. Mainous AG III, Diaz VA, Geesey ME. Acculturation and healthy lifestyle among Latinos with diabetes. Ann Fam Med. 2008;6(2):131-7.

10. Viruell-Fuentes EA. Beyond acculturation: immigration, discrimination, and health research among Mexicans in the United States. Soc Sci Med. 2007;65(7):1524-35.

11. Barcenas $\mathrm{CH}$, Wilkinson $\mathrm{AV}$, Strom SS, et al. Birthplace, years of residence in the United States, and obesity among Mexican-American adults. Obesity (Silver Spring). 2007;15(4): 1043-52.

12. Eamranond PP, Patel KV, Legedza AT, Marcantonio ER, Leveille SG. The association of language with prevalence of undiagnosed hypertension among older Mexican Americans. Ethn Dis. 2007;17(4):699-706.

13. Perez-Escamilla R, Putnik P. The role of acculturation in nutrition, lifestyle, and incidence of type 2 diabetes among Latinos. J Nutr. 2007;137(4):860-70.
14. Romero AJ, Martinez D, Carvajal SC. Bicultural stress and adolescent risk behaviors in a community sample of Latinos and nonLatino European Americans. Ethn Health. 2007;12(5):443-63.

15. Steffen PR, Smith TB, Larson M, Butler L. Acculturation to Western society as a risk factor for high blood pressure: a metaanalytic review. Psychosom Med. 2006;68(3):386-97.

16. Antecol H, Bedard K. Unhealthy assimilation: why do immigrants converge to American health status levels? Demography. 2006;43(2):337-60.

17. Abraido-Lanza AF, Armbrister AN, Florez KR, Aguirre AN. Toward a theory-driven model of acculturation in public health research. Am J Public Health. 2006;96(8):1342-6.

18. Fitzgerald N, Himmelgreen D, Damio G, Segura-Perez S, Peng YK, Perez-Escamilla R. Acculturation, socioeconomic status, obesity and lifestyle factors among low-income Puerto Rican women in Connecticut, US 1998-1999. Rev Panam Salud Publica. 2006;19(5):306-13.

19. Mainous AG III, Majeed A, Koopman RJ, et al. Acculturation and diabetes among Hispanics: evidence from the 1999-2002 National Health and Nutrition Examination Survey. Public Health Rep. 2006;121(1):60-6.

20. Abraido-Lanza AF, Chao MT, Florez KR. Do healthy behaviors decline with greater acculturation? Implications for the Latino mortality paradox. Soc Sci Med. 2005;61(6):1243-55.

21. Singh GK, Miller BA. Health, life expectancy, and mortality patterns among immigrant populations in the United States. Can J Public Health. 2004;95(3):I14-21.

22. Messias DK, Rubio M. Immigration and health. Annu Rev Nurs Res. 2004;22:101-34.

23. Franzini L, Fernandez-Esquer ME. Socioeconomic, cultural, and personal influences on health outcomes in low income Mexicanorigin individuals in Texas. Soc Sci Med. 2004;59(8):1629-46.

24. Landrine H, Klonoff EA. Culture change and ethnic-minority health behavior: an operant theory of acculturation. J Behav Med. 2004;27(6):527-55.

25. McCarthy LH, Bigal ME, Katz M, Derby C, Lipton RB. Chronic pain and obesity in elderly people: results from the Einstein aging study. J Am Geriatr Soc. 2009;57(1):115-9.

26. Guh DP, Zhang W, Bansback N, Amarsi Z, Birmingham CL, Anis AH. The incidence of co-morbidities related to obesity and overweight: a systematic review and meta-analysis. BMC Public Health. 2009;9(1):88.

27. Shiri R, Solovieva S, Husgafvel-Pursiainen K, et al. The association between obesity and the prevalence of low back pain in young adults: the cardiovascular risk in Young Finns Study. Am J Epidemiol. 2008;167(9):1110-9.

28. Anandacoomarasamy A, Caterson I, Sambrook P, Fransen M, March L. The impact of obesity on the musculoskeletal system. Int J Obes (Lond). 2008;32(2):211-22.

29. Sach TH, Barton GR, Doherty M, Muir KR, Jenkinson C, Avery AJ. The relationship between body mass index and health-related quality of life: comparing the EQ-5D, EuroQol VAS and SF-6D. Int J Obes (Lond). 2007;31(1):189-96.

30. Webb R, Brammah T, Lunt M, Urwin M, Allison T, Symmons D. Prevalence and predictors of intense, chronic, and disabling neck and back pain in the UK general population. Spine. 2003;28(11): 1195-202.

31. Deyo RA, Bass JE. Lifestyle and low-back pain. The influence of smoking and obesity. Spine. 1989;14(5):501-6.

32. Patten SB, Williams JV, Lavorato DH, Modgill G, Jette N, Eliasziw M. Major depression as a risk factor for chronic disease incidence: longitudinal analyses in a general population cohort. Gen Hosp Psychiatry. 2008;30(5):407-13.

33. Tsang A, Von Korff M, Lee S, et al. Common chronic pain conditions in developed and developing countries: gender and age 
differences and comorbidity with depression-anxiety disorders. J Pain. 2008;9(10):883-91.

34. Thelin A, Holmberg S, Thelin N. Functioning in neck and low back pain from a 12-year perspective: a prospective populationbased study. J Rehabil Med. 2008;40(7):555-61.

35. Tang NK, Salkovskis PM, Hodges A, Wright KJ, Hanna M, Hester J. Effects of mood on pain responses and pain tolerance: an experimental study in chronic back pain patients. Pain. 2008;138(2):392-401.

36. Schiphorst Preuper HR, Reneman MF, Boonstra AM, et al. Relationship between psychological factors and performancebased and self-reported disability in chronic low back pain. Eur Spine J. 2008;17(11):1448-56.

37. Keeley P, Creed F, Tomenson B, Todd C, Borglin G, Dickens C. Psychosocial predictors of health-related quality of life and health service utilisation in people with chronic low back pain. Pain. 2008;135(1-2):142-50.

38. Aceves-Gonzalez C, Prado-Leon LR. Low back pain and depression: a study in a population of Mexican workers. Work. 2008;31(2):159-66.

39. Baune BT, Caniato RN, Garcia-Alcaraz MA, Berger K. Combined effects of major depression, pain and somatic disorders on general functioning in the general adult population. Pain. 2008; 138(2):310-7.

40. Von Korff M, Dworkin SF, Le Resche L, Kruger A. An epidemiologic comparison of pain complaints. Pain. 1988;32(2):173-83.

41. McBeth J, Jones K. Epidemiology of chronic musculoskeletal pain. Best Pract Res Clin Rheumatol. 2007;21(3):403-25.

42. Rubin DI. Epidemiology and risk factors for spine pain. Neurol Clin. 2007;25(2):353-71.

43. Fishbain DA, Lewis JE, Gao J, Cole B, Steele Rosomoff R. Are chronic low back pain patients who smoke at greater risk for suicide ideation? Pain Med Mar. 2009;10(2):340-6.

44. Palmer B, Macfarlane G, Afzal C, Esmail A, Silman A, Lunt M. Acculturation and the prevalence of pain amongst South Asian minority ethnic groups in the UK. Rheumatology (Oxford). 2007; 46(6):1009-14.

45. Soares JJ, Grossi G. Experience of musculoskeletal pain. Comparison of immigrant and Swedish patient. Scand J Caring Sci. 1999;13(4):254-66.

46. Lofvander M, Taloyan M. Pain intensity and severe pain in young immigrant patients with long-standing back pain. Eur Spine J. 2008;17(1):89-96.

47. Lofvander MB, Furhoff AK. Pain behaviour in young immigrants having chronic pain: an exploratory study in primary care. Eur $\mathbf{J}$ Pain. 2002;6(2):123-32.

48. Lofvander M. Attitudes towards pain and return to work in young immigrants on long-term sick leave. Scand J Prim Health Care. 1999;17(3):164-9.

49. Heeringa SG. Technical sample design documentation: 2002-2003 National Latino and Asian American Study (NLAAS). Ann Arbor, MI: Institute for Social Research, University of Michigan Ann Arbor; 2004.

50. Pennell BE, Bowers A, Carr D, et al. The development and implementation of the National Comorbidity Survey Replication, the National Survey of American Life, and the National Latino and Asian American Survey. Int J Methods Psychiatr Res. 2004; 13(4):241-69.

51. Heeringa SG, Wagner J, Torres M, Duan N, Adams T, Berglund P. Sample designs and sampling methods for the Collaborative Psychiatric Epidemiology Studies (CPES). Int J Methods Psychiatr Res. 2004;13(4):221-40.

52. Disability Assessment Schedule II (WHODAS II). Geneva, Switzerland: World Health Organization; 1998.

53. Cortes DE. Acculturation and its relevance to mental health. In: Malgady RG, Rodriguez O, editors. Theoretical and conceptual issues in Hispanic mental health. Malabar, FL: Kreiger; 1994. p. $54-67$.

54. Negy C, Wood DJ. The importance of acculturation in understanding research with Hispanic Americans. Hispanic J Behav Sci. 1992;14(2):224-47.

55. Kessler RC, Ustun TB. The World Mental Health (WMH) Survey Initiative Version of the World Health Organization (WHO) Composite International Diagnostic Interview (CIDI). Int J Methods Psychiatr Res. 2004;13(2):93-121.

56. STATA/SE [computer program]. Version 9.2. College Station, TX: STATA Corporation; 2007.

57. Rust KF. Variance estimation for complex estimators in sample surveys. J Off Stat. 1985;1(4):381-97.

58. Zhang J, Yu KF. What's the relative risk? A method of correcting the odds ratio in cohort studies of common outcomes. JAMA. 1998;280(19):1690-1.

59. Volinn E. The epidemiology of low back pain in the rest of the world. A review of surveys in low- and middle-income countries. Spine. 1997;22(15):1747-54.

60. Raspe H, Matthis C, Croft P, O'Neill T. Variation in back pain between countries: the example of Britain and Germany. Spine. 2004;29(9):1017-21. discussion 1021.

61. Scott KM, Bruffaerts R, Tsang A, et al. Depression-anxiety relationships with chronic physical conditions: results from the World Mental Health Surveys. J Affect Disord. 2007;103(1-3):113-20.

62. Demyttenaere K, Bruffaerts R, Lee S, et al. Mental disorders among persons with chronic back or neck pain: results from the World Mental Health Surveys. Pain. 2007;129(3):332-42.

63. Alegria M, Takeuchi D, Canino G, et al. Considering context, place and culture: the National Latino and Asian American Study. Int J Methods Psychiatr Res. 2004;13(4):208-20.

64. Pincus T, Santos R, Breen A, Burton AK, Underwood M. A review and proposal for a core set of factors for prospective cohorts in low back pain: a consensus statement. Arthritis Rheum. 2008;59(1):14-24.

65. Baker MM, Stabile M, Deri C. What do self-reported, objective measures of health measure?. Cambridge MA: National Bureau of Economic Research; 2001.

66. Edwards WS, Winn DM, Kurlantzick V, et al. Evaluation of National Health Interview Survey Diagnostic Reporting 2. Vital Health Stat. 1994;120:1-116.

67. Knight M, Stewart-Brown S, Fletcher L. Estimating health needs: the impact of a checklist of conditions and quality of life measurement on health information derived from community surveys. J Public Health Med. 2001;23(3):179-86. 